\title{
ORIGINAL ARTICLE Geospatial relationships of air pollution and acute asthma events across the Detroit-Windsor international border: Study design and preliminary results
}

\author{
Lawrence D. Lemke ${ }^{1}$, Lois E. Lamerato ${ }^{2}$, Xiaohong $\mathrm{Xu}^{3}$, Jason C. Booza ${ }^{4}$, John J. Reiners Jr ${ }^{5}$, Delbert M. Raymond III ${ }^{6}$,
} Paul J. Villeneuve ${ }^{7,8}$, Eric Lavigne ${ }^{9}$, Dana Larkin ${ }^{2}$ and Helene J. Krouse ${ }^{10}$

The Geospatial Determinants of Health Outcomes Consortium (GeoDHOC) study investigated ambient air quality across the international border between Detroit, Michigan, USA and Windsor, Ontario, Canada and its association with acute asthma events in 5- to 89-year-old residents of these cities. $\mathrm{NO}_{2}, \mathrm{SO}_{2}$, and volatile organic compounds (VOCs) were measured at 100 sites, and particulate matter (PM) and polycyclic aromatic hydrocarbons (PAHs) at 50 sites during two 2-week sampling periods in 2008 and 2009. Acute asthma event rates across neighborhoods in each city were calculated using emergency room visits and hospitalizations and standardized to the overall age and gender distribution of the population in the two cities combined. Results demonstrate that intra-urban air quality variations are related to adverse respiratory events in both cities. Annual 2008 asthma rates exhibited statistically significant positive correlations with total VOCs and total benzene, toluene, ethylbenzene and xylene (BTEX) at 5-digit zip code scale spatial resolution in Detroit. In Windsor, $\mathrm{NO}_{2}, \mathrm{VOCs}$, and $\mathrm{PM}_{10}$ concentrations correlated positively with 2008 asthma rates at a similar 3-digit postal forward sortation area scale. The study is limited by its coarse temporal resolution (comparing relatively short term air quality measurements to annual asthma health data) and interpretation of findings is complicated by contrasts in population demographics and health-care delivery systems in Detroit and Windsor.

Journal of Exposure Science and Environmental Epidemiology (2014) 24, 346-357; doi:10.1038/jes.2013.78; published online 13 November 2013

Keywords: asthma; air pollution; Detroit; Windsor; international; geospatial

\section{INTRODUCTION}

A growing body of epidemiological research has shown that ambient air pollution, and in particular traffic-related air pollution, is a contributing cause of premature mortality and morbidity. ${ }^{1,2}$ Recent studies have reported adverse respiratory events from exposure to traffic emissions with intensified effects in children. ${ }^{3-5}$ A systematic review of the research on long-term exposure to ambient air pollution and chronic diseases also suggests an increased morbidity and mortality in adults from lung cancer, cardiovascular diseases, and respiratory conditions. ${ }^{6}$ Major urban air pollutants such as nitrogen dioxide $\left(\mathrm{NO}_{2}\right)$, a recognized marker of traffic-related pollution, have been associated with higher rates of respiratory morbidity, ${ }^{8}$ particularly asthma. ${ }^{9,10}$ Few studies, however, have evaluated the spatial and temporal variability of air quality and its effects on health conditions between adjacent international cities sharing a common airshed. The international context of this study provides unique opportunities to compare population health outcomes in response to environmental conditions in adjoining cities with different environmental regulations, public health policies, and health-care delivery systems.

Epidemiological analyses of the health-related effects of air pollution are complicated by the need for accurate characterization of the effects from exposure to airborne pollutants (e.g., increased asthma exacerbations) and the availability of information indicative of exposure (e.g., ambient air quality measurements). Accurate characterization of exposure gradients for all members of a given study population is particularly challenging because routine monitoring networks rarely have enough sites to capture smallscale spatial variability within a city. The significance of monitoring resolution is emphasized by findings that urban $\mathrm{NO}_{2}$ concentrations measured $50 \mathrm{~m}$ apart can vary by as much as $300 \%{ }^{11}$ and that traffic-related pollutants fall off to background levels within $300 \mathrm{~m}$ of major roadways. ${ }^{12,13}$ Additionally, recent studies suggest that intra-urban exposure to airborne pollutants may be associated with larger health effects than inter-urban variability. ${ }^{14,15}$ Consequently, there is a need to characterize intra-urban gradients for pollutants at neighborhood scales particularly for studies focused on characterizing adverse health effects associated with long-term exposure. This can be accomplished by establishing short-term multi-site measurement networks (i.e., saturation monitoring ${ }^{16}$ ).

In addition, air pollutant concentrations also vary over time so that exposure is a function of both 'where' you are as well as 'when' you are there. Temporal variability has been documented on hourly, diurnal, and seasonal time scales, each of which may be important for asthma exacerbation or prevalence. For example, significant

${ }^{1}$ Department of Geology, Wayne State University, Detroit, Michigan, USA; ${ }^{2}$ Department of Public Health Sciences, Henry Ford Health System, Detroit, Michigan, USA; ${ }^{3}$ Department of Civil and Environmental Engineering, University of Windsor, Windsor, Ontario, Canada; ${ }^{4}$ Department of Academic and Student Programs, Wayne State University, Detroit, Michigan, USA; ${ }^{5}$ Institute of Environmental Health Sciences, Wayne State University, Detroit, Michigan, USA; ${ }^{6}$ School of Nursing, Eastern Michigan University, Ypsilanti, Michigan, USA; ${ }^{7}$ Department of Health Sciences, Carleton University, Ottawa, Ontario, Canada; ${ }^{8}$ Dalla Lana School of Public Health, University of Toronto, Toronto, Ontario, Canada; ${ }^{9}$ Environmental Issues Division, Public Health Agency of Canada, Ottawa, Ontario, Canada and ${ }^{10}$ College of Nursing, Wayne State University, Detroit, Michigan, USA. Correspondence to: Dr LD Lemke, Department of Geology, Wayne State University, Room 0224 Old Main, Detroit, MI 48202, USA.

Tel: +1-313-577-6412. Fax: +1-313-577-0517.

E-mail: Idlemke@wayne.edu

Received 12 April 2013; revised 30 July 2013; accepted 11 September 2013; published online 13 November 2013 
associations have been documented between high pollutant concentrations and asthma hospitalizations ${ }^{17}$ and other respiratory symptoms ${ }^{18}$ with time lags ranging from 0 to 5 days. In another analysis, temporal variability exceeded spatial variability for widely spaced measurements of 39 volatile organic compounds, carbonyl compounds, trace elements, and extractable organic mass species in an urban area. ${ }^{19}$ Consequently, the questions of how, when, and where to measure or estimate exposure to airborne contaminants are of fundamental importance when assessing health outcomes.

Air Quality Studies in Detroit and Windsor

Detroit, Michigan and Windsor, Ontario, are neighboring cities separated by the Detroit River along the USA-Canada border. The economies of both cities share strong ties to the automotive industry along with high air pollution levels relative to most North American cities. Concerns about air quality have motivated recent, separate exposure studies in each city. In Windsor, land-use regression (LUR) models were developed for $\mathrm{NO}_{2}, \mathrm{SO}_{2}$, benzene, and toluene concentrations measured with a dense network of 50 monitors during 2-week sampling periods in each of the four seasons of 2004. ${ }^{20,21}$ Later, the Windsor, Ontario Exposure Assessment Study (WOEAS) utilized personal, indoor and outdoor monitors to estimate the exposure of adults and asthmatic children living in Windsor to air pollutants in 2005 and 2006. ${ }^{22}$ Most recently, positive associations were found between emergency department visits for asthma and air pollution measured at central monitoring stations in Windsor from 2002 to $2009 .^{23}$

In Detroit, the Detroit Air Toxics Pilot Study demonstrated variability of particulate matter and air toxics measured at eight

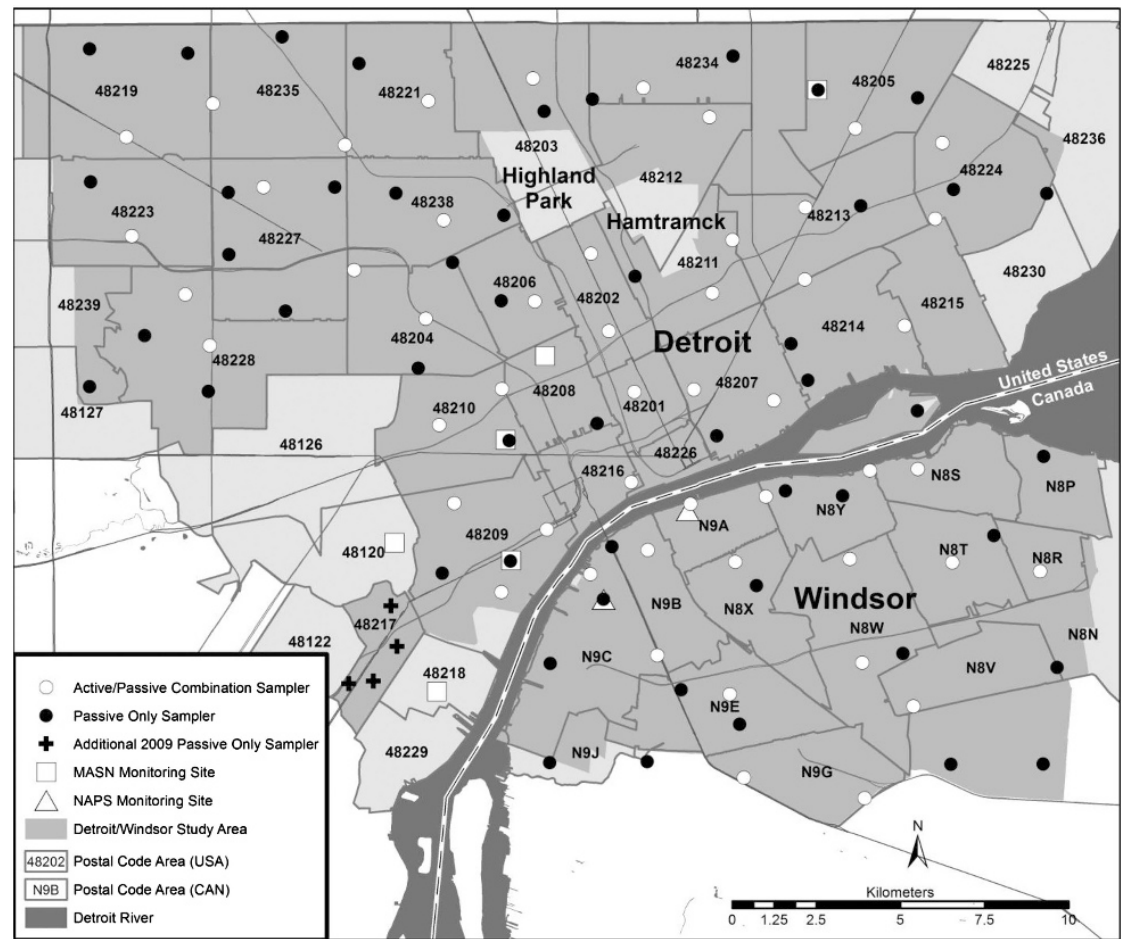

Figure 1. Detroit/Windsor study area with sampler locations and postal code areas.

Table 1. Instrumentation, sample preparation and laboratory analysis.

\begin{tabular}{|c|c|c|c|c|}
\hline Analyte & $\begin{array}{l}\text { Sampling } \\
\text { type }\end{array}$ & Sampler & Sampler preparation & Laboratory analysis \\
\hline $\mathrm{NO}_{2}$ and $\mathrm{SO}_{2}$ & Passive & Ogawa diffusion samplers & $\begin{array}{l}\text { Pretreated filter obtained } \\
\text { from Ogawa }\end{array}$ & $\begin{array}{l}\text { Environment Canada (Egbert, Ontario) } \\
\text { using ion chromatography }\end{array}$ \\
\hline VOC & Passive & 3M \#3500 organic vapor monitor & Obtained from $3 \mathrm{M}$ & $\begin{array}{l}\text { Airzone One (Mississauga, Ontario), gas } \\
\text { chromatography/mass selective } \\
\text { detector with species dependent } \\
\text { detection limits, } 26 \text { VOCs }\end{array}$ \\
\hline PM & Active & $\begin{array}{l}\text { 3-stage Harvard Cascade Impactors; } \\
\text { SKC Leland Legacy pump at } 5.0 \mathrm{Lpm} \\
\text { flow rate; } \\
\mathrm{PM}_{1} \text { on a Teflon filter, } \mathrm{PM}_{1-2.5} \text { and } \\
\mathrm{PM}_{2.5-10} \text { on individual Polyurethane } \\
\text { Foams (PUFs) }\end{array}$ & $\begin{array}{l}\text { Teflon filter and PUFs } \\
\text { conditioned before and after } \\
\text { sampling, Alberta Research } \\
\text { Council (Vegreville, Alberta) }\end{array}$ & $\begin{array}{l}\text { Alberta Research Council, gravimetric } \\
\text { method with lab detection limit of } \\
4 \mu \mathrm{g} / \text { filter }\end{array}$ \\
\hline
\end{tabular}


Table 2. Sampler retention and species included in September 2008 and June 2009 analyses.

\begin{tabular}{|c|c|c|c|c|c|c|c|c|}
\hline \multirow[t]{2}{*}{ Pollutant } & \multicolumn{4}{|c|}{ September 5-20 2008} & \multicolumn{4}{|c|}{ May 29-June 132009} \\
\hline & $\begin{array}{l}\text { Samplers } \\
\text { deployed }\end{array}$ & $\begin{array}{l}\text { Samplers } \\
\text { retrieved }\end{array}$ & $\begin{array}{l}\text { Samples } \\
\text { accepted }\end{array}$ & $\begin{array}{c}\text { Species included in } \\
\text { analysis }\end{array}$ & $\begin{array}{l}\text { Samplers } \\
\text { deployed }\end{array}$ & $\begin{array}{l}\text { Samplers } \\
\text { retrieved }\end{array}$ & $\begin{array}{l}\text { Samples } \\
\text { accepted }\end{array}$ & $\begin{array}{c}\text { Species included in } \\
\text { analysis }\end{array}$ \\
\hline $\mathrm{NO}_{2}$ & 100 & 99 & 98 & Included & 100 & 100 & 93 & Included \\
\hline $\mathrm{SO}_{2}$ & 100 & 99 & 98 & Excluded & 100 & 100 & 90 & Included \\
\hline VOCs & 100 & 100 & 98 & 12 out of 26 & 100 & 100 & 99 & 9 out of 26 \\
\hline PAHs & 50 & 50 & 38 & 16 out of 23 & 50 & 50 & 40 & 8 out of 23 \\
\hline PM & 50 & 50 & 38 & Included & 50 & 50 & 38 & Included \\
\hline
\end{tabular}

Table 3. Detroit and Windsor population demographics (\%).

\begin{tabular}{|c|c|c|c|}
\hline & $\begin{array}{l}\text { Detroit } \\
2010^{\mathrm{a}}\end{array}$ & $\begin{array}{l}\text { HFHS Detroit } \\
2008^{\mathrm{b}}\end{array}$ & $\begin{array}{l}\text { Windsor } \\
2006^{c}\end{array}$ \\
\hline Male & 47.3 & 39.2 & 48.8 \\
\hline Female & 52.7 & 60.8 & 51.2 \\
\hline Age 5-14 & 14.3 & 10.9 & 12.3 \\
\hline Age 15-44 & 41.9 & 48.5 & 43.3 \\
\hline Age $45-64$ & 25.4 & 26.3 & 24.1 \\
\hline Age $65+$ & 11.4 & 7.9 & 14.3 \\
\hline Total & 93.0 & 93.7 & 94.0 \\
\hline $\begin{array}{l}\text { White }{ }^{\mathrm{d}} / \text { not a visible } \\
\text { minority }^{\mathrm{e}}\end{array}$ & 10.6 & 12.3 & 79.0 \\
\hline $\begin{array}{l}\text { Black or African } \\
\text { American }^{\mathrm{d}} / \text { Black }^{\mathrm{e}}\end{array}$ & 82.7 & 78.6 & 3.9 \\
\hline Other & 6.7 & 9.2 & 17.1 \\
\hline
\end{tabular}

locations in the Detroit metropolitan area in 2001 and 2002. ${ }^{24}$ Subsequently, the Detroit Exposure and Aerosol Research Study (DEARS) compared air pollutant concentrations measured at a central monitoring site with indoor, outdoor, and personal monitoring measurements distributed throughout six Detroit neighborhoods from 2004 to $2007 .{ }^{25}$ Although the spatial resolution of the outdoor measurements was limited, the DEARS study found spatial variability and gradients in ambient concentrations of particulate matter ${ }^{26,27}$ and volatile organic compounds. ${ }^{28}$ Modest associations were found between community-based and personal exposure measurements of $\mathrm{NO}_{2}$ in the DEARS study. ${ }^{29}$

\section{Study Objectives}

The Geospatial Determinants of Health Outcomes Consortium (GeoDHOC) study was designed to explore associations between short-term ambient air pollution concentrations and acute asthma events at a high level of spatial resolution. Our approach is motivated by the expectation that correlations among mappable environmental attributes and health indicators can be used to better understand and manage urban community health. Specific aims included (1) collection and modeling of simultaneous air pollutant concentrations in Detroit and Windsor, (2) collection of concurrent data on asthma prevalence using asthma-related patient encounters, and asthma exacerbations using asthmarelated emergency department visits and hospital discharge records in Detroit and Windsor, (3) integration of the environmental and asthma data into a geographic information system (GIS) database, and (4) analysis of spatial associations among air quality and asthma metrics. This paper provides an overview of the GeoDHOC project by describing the study design, implementation strategies, and initial findings for spatial models relating pollutant distributions to acute asthma events in Detroit and Windsor.

\section{METHODS}

Geospatial Database

A geospatial database was developed to manage the large amount of information needed for this study. Data assembled for use in sampler allocation and land-use regression modeling included population characteristics, land-use characteristics, proximity-to-point sources in the US Toxics Release Inventory ${ }^{30}$ and the Canadian National Pollutant Release Inventory, ${ }^{31}$ topography, traffic volumes, and road networks. These public data were obtained through local, state/provincial, and national sources including the Southeast Michigan Council of Governments, US Environmental Protection Agency, US National Oceanic and Atmospheric Administration, City of Windsor GIS Division and Infrastructure Services, Essex Region Conservation Authority, Statistics Canada, and Environment Canada. Together with air sampling and health data, these data sets were integrated into a GIS to facilitate data visualization and geospatial modeling.

Data rectification. Configuration of disparate data sets across the international study area (Figure 1) posed a significant database management challenge. Despite the proximity of Detroit and Windsor, many of the geographic data files used in this study had different geospatial projections (UTM versus State Plane), measurement systems (imperial versus metric), data collection methodologies (e.g., traffic counts, emissions inventories), scalar resolutions, or typologies (e.g., land use). In addition, data files were formatted for use in different software programs (e.g., MapInfo versus ESRI ArcGIS).

If data from one city were more complete or of a higher resolution, they were reduced to the standards of the lesser quality data for comparative purposes. In many cases, data quality was high for both cities, but data sets contained different typologies. For example, road and land-use classifications are different in Detroit and Windsor. Thus, data categories for both cities were reclassified to create a new merged standard without deterioration in data quality. In other cases, such as point source emissions data, differences in reporting conventions between the US and Canada required us to keep the information in its original format.

\section{Air Quality Sampling Methods}

Air sampling involved a combination of 50 paired active/passive and 50 passive-only devices deployed at 100 sampling sites. ${ }^{32}$ Two sampling rounds of 2-week duration were conducted, the first in September 2008 and the second in June 2009. Measured pollutants included $\mathrm{NO}_{2}, \mathrm{SO}_{2}, \mathrm{PM}_{1}$ (particulate matter $<1 \mu \mathrm{m}$ in aerodynamic diameter), $\mathrm{PM}_{1-2.5}, \mathrm{PM}_{2.5-10}$ and selected volatile organic compounds (VOCs) and polycyclic aromatic hydrocarbons (PAHs). These pollutants were selected for reasons including their known influence on respiratory health, their relationship to land use and traffic, and investigator experience measuring them in Windsor and other cities.

Air sampling equipment. Air sampler specifications are given in Table 1. Equipment included 50 sets of active air monitoring equipment using SKC Leland Legacy sampling pumps (SKC Inc., Eighty Four, PA, USA) powered by an AC adapter and housed in weatherproof cases. The pumps ensured sufficient air flow to operate Harvard Cascade Impactor particulate monitors (Harvard School of Public Health, Boston, MA, USA) and URG personal pesticide samplers (model URG-2000-25AB, Chapel Hill, NC, USA). The latter were used to measure PAHs. Additional sampling equipment included 100 sets of passive diffusion monitors consisting of a rain shield and mounting bracket to hold the Ogawa passive badges (Ogawa \& Co, Pompano Beach, $\mathrm{FL}, \mathrm{USA}$ ) used to monitor $\mathrm{NO}_{2}$ and $\mathrm{SO}_{2}$, and the $3 \mathrm{M}$ Model 3500 Organic Vapor Samplers (3M Canada, London, Ontario) used to 


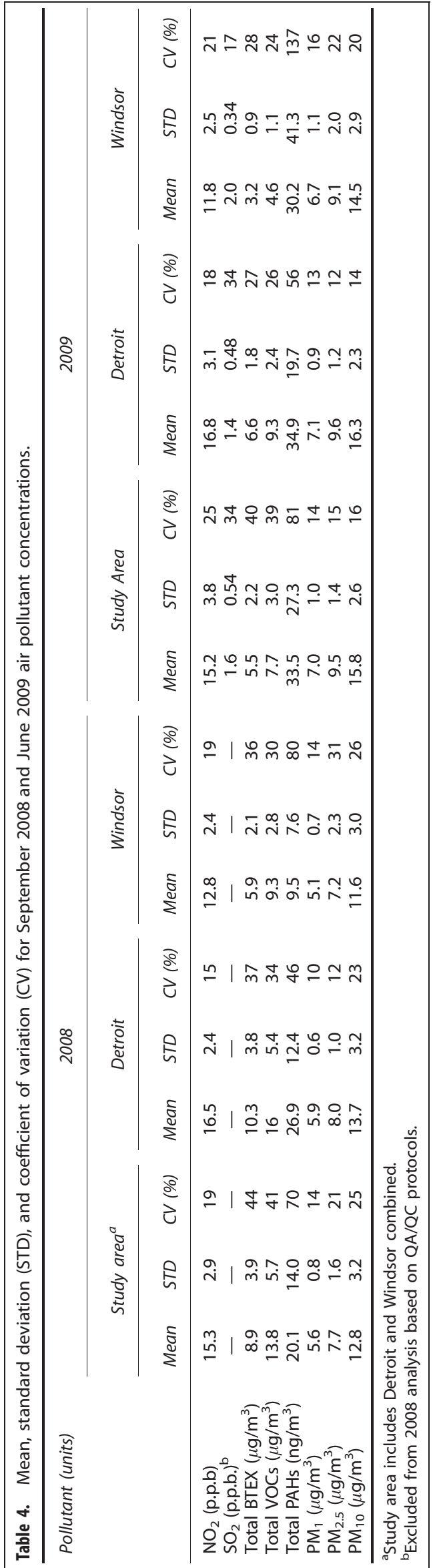

measure 26 different VOCs, including benzene, toluene, ethylbenzene, and xylene (BTEX).

Sampler allocation. Existing data on transportation routes, population density, and the location of suitable sampling facilities were analyzed to design a sampler allocation plan for the study. Constraints included the number of available air sampling units and the need for safe and secure locations with a continuous power supply for active samplers. Methods employed by others including location-allocation modeling, ${ }^{33}$ criteriabased targeted sampling, ${ }^{34}$ and uniform distribution sampling ${ }^{35}$ were considered. However, the absence of requisite mapped pollution gradients for Detroit and an at-risk population gradient for Windsor precluded location-allocation and criteria-based targeted sampling. Consequently, a site-specific methodology was developed for this study.

Initially, we used land area and city shapes to determine that a Detroit:Windsor sampler ratio of 34:16 would optimize the desired spatially stratified sampling design. Allocation of individual samplers then proceeded in two steps to accommodate the need to locate paired active/passive and passive-only samplers. Based on our need for a continuous power supply and security concerns, active/passive samplers were placed at fire and police stations in Detroit and municipal and nonprofit institutions in Windsor. Specific sites were selected to lie as close as possible to the centroid of a $3 \times 3 \mathrm{~km}$ cell grid pattern overlain on each city. Passive samplers were then allocated within the same $3 \mathrm{~km}$ grid, with first priority given to cells that did not contain a paired active/passive sampler. Secondary priority was given to maximizing distance from other samplers, minimizing proximity to schools, and collocation of samplers with permanent governmental air monitoring sites in Detroit and Windsor and six sites tied to prior studies in Windsor. ${ }^{21}$ Collocated sites were used for measurement validation. ${ }^{32}$ The average spatial resolution of the sampling design across the study area is 1 measurement per $5 \mathrm{~km}^{2}$ for passive samplers, and 1 measurement per $10 \mathrm{~km}^{2}$ for active samplers.

Preparation and transport of air samplers. Measures were undertaken to ensure consistency and reliability in sampling across the international airshed. Monitoring equipment and samplers were prepared at the University of Windsor following rigorous quality control procedures. Samplers with prepared filters were transported in sealed bags inside coolers to maintain a constant temperature and prevent contamination or off gassing in transit prior to deployment at predetermined sampling sites in Detroit and Windsor. Detroit samplers were carried across the international border by private automobile (as opposed to commercial transport) so that study investigators could remain with the samples to avert contamination during border inspection. Customs officials on each side of the border were notified in advance of shipments and X-ray inspection was requested to avoid exposing filters to ambient air and temperature changes (both prior to deployment and following air sample collection). Transportation by car also helped minimize delays inherent in commercial international shipping.

Sampler deployment and retrieval. Samplers were distributed between Detroit and Windsor (Table 2) based on the allocation method described above. Combined active and passive samplers were deployed at 50 locations on the first day of each sampling round, and 50 additional passive-only samplers were deployed on the second day. Samplers were deployed on light poles, downspouts, and tripods at predetermined specified heights above the ground in both cities. ${ }^{32}$ All samplers were retrieved 2 weeks after their initial deployment. Municipal and logistical constraints necessitated the movement of six sampling sites between the September 2008 and June 2009 sampling events. Relocated sites were placed within $200 \mathrm{~m}$ of the original locations. Four additional passive sites were added in the 48217 zip code area in 2009 to extend coverage within southwest Detroit.

Quality assurance. Quality assurance (QA) and quality control (QC) measures were applied to ensure consistency, reliability, and reproducibility of the study results. Field equipment was tested and calibrated prior to deployment. Samples were handled and stored by trained technicians using written standardized operating procedures to enforce sampling consistency and minimize potential contamination. Field and laboratory blanks were deployed to quantify the sample mass attributable to handling and transportation. Because of the many samples and sampling stages involved, an internal sample manifest, nomenclature, and tracking procedure was implemented including log sheets and chain of custody records. Deviations from the established protocol were noted and log 
a

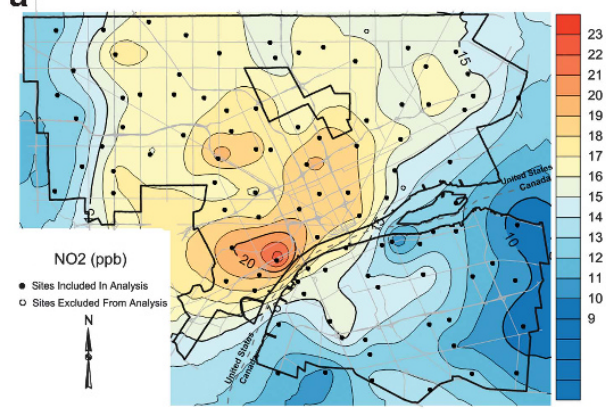

b

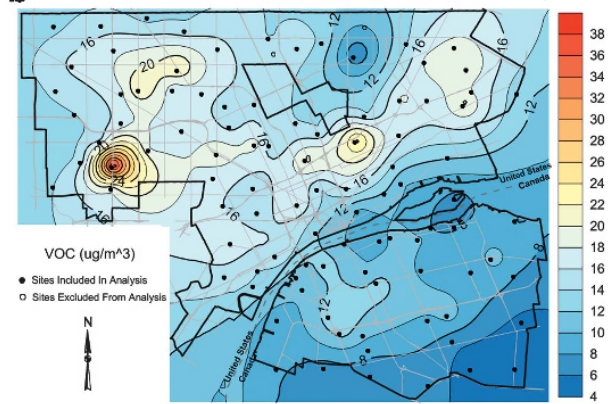

c

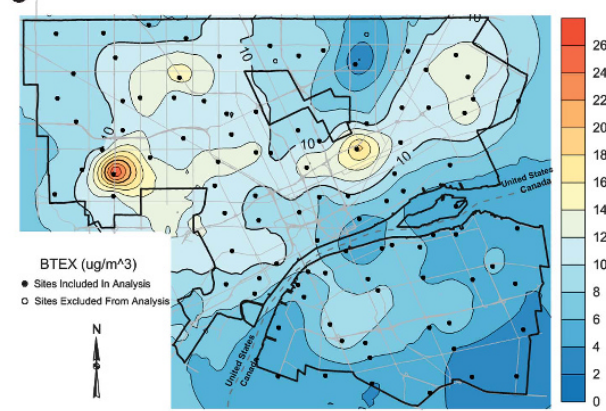

d

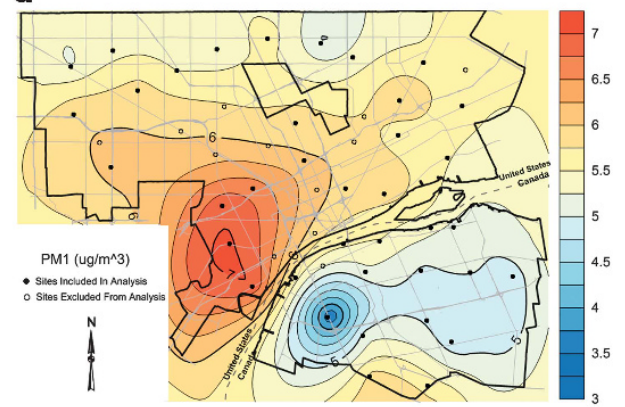

e

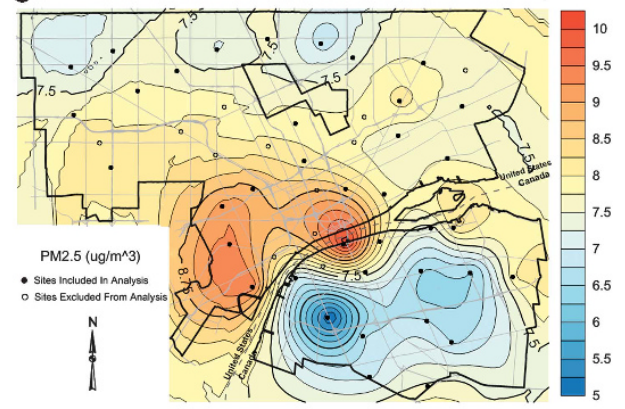

$\mathbf{f}$

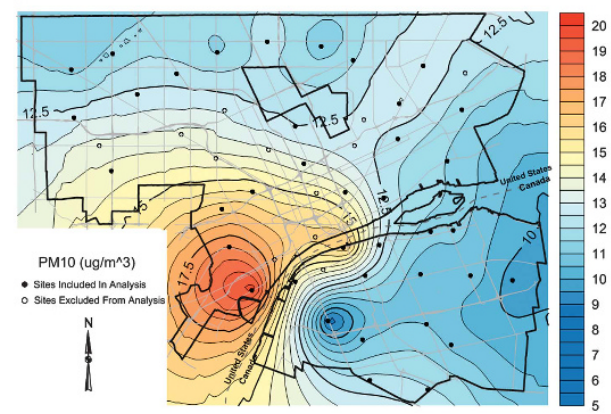

Figure 2. September 2008 mapped concentrations for: (a) $\mathrm{NO}_{2}$ (p.p.b.); (b) VOC $\left(\mu \mathrm{g} / \mathrm{m}^{3}\right) ;(\mathbf{c}) \mathrm{BTEX}\left(\mu \mathrm{g} / \mathrm{m}^{3}\right) ;(\mathbf{d}) \mathrm{PM}_{1}\left(\mu \mathrm{g} / \mathrm{m}^{3}\right) ;(\mathbf{e}) \mathrm{PM} 2.5\left(\mu \mathrm{g} / \mathrm{m}^{3}\right)$; and (f) $\mathrm{PM}_{10}\left(\mu \mathrm{g} / \mathrm{m}^{3}\right)$.

sheets were reviewed for discrepancies or unexplained observations. After retrieval, samplers with out-of-tolerance flow rates, insufficient pump run times, or evidence of tampering were excluded from further analysis (Table 2). In addition, individual species with $<80 \%$ of sites registering values above laboratory detection limits were excluded from further analysis (Table 2). A more detailed description of sampling methods, precision of instruments, and QA/QC procedures employed is given by Miller et al. ${ }^{32}$ and Wheeler et al. ${ }^{22}$

\section{Health Data Census Methods}

Study population. Individuals 5-89 years of age living in the Detroit and Windsor metropolitan areas are the population of interest for this study. Asthma is the health outcome of interest. Children under the age of 5 were excluded because objective measures of lung function such as spirometry are standardized only for individuals 5 years of age and older, and it is often difficult to differentiate asthma from other respiratory conditions in very young children. ${ }^{36}$

Patient demographics. As of 2010, Detroit had $\sim 714,000$ residents; $\sim 30 \%$ were under 20 years of age and $11 \%$ were 65 years and older. ${ }^{37}$ In 2008 , the Henry Ford Health System (HFHS) provided health-care services to $>125,000$ Detroit residents. The demographics of HFHS patients living in Detroit generally reflect those of Detroit-the majority of the HFHS Detroit patient population is African American, but a larger proportion of HFHS patients are female (Table 3). HFHS patients residing in Detroit had $\sim 400$ hospital admissions and 2,500 emergency room visits for asthma in 2008.
Windsor, similar to Detroit, is a diverse city that is home to many ethnic and racial groups. According to the 2006 census, $^{38} \sim 25 \%$ of Windsor residents are under 20 years of age and $14 \%$ of the population is 65 years and older (Table 3). In contrast to Detroit, where $\sim 80 \%$ of the population is African American, a small minority (4\%) of Windsor residents are black and other ethnic and racial groups comprise $17 \%$ of the population (Table 3). Windsor Regional Hospital (Metropolitan Campus and Western Campus) and Hotel Dieu Grace Hospital are the main medical facilities. Together, their campuses experienced 423,000 ambulatory visits in 2007/2008. ${ }^{39}$ Hospitalization data are captured in two national databases maintained by the Canadian Institute for Health Information $(\mathrm{CIHI})$ : the Discharge Abstract Database $(D A D)^{40}$ for hospital admissions, and the National Ambulatory Care Reporting System (NACRS) ${ }^{41}$ for emergency room visits. In order to avoid duplicate counts (i.e., a patient admitted to the emergency room and subsequently admitted to the hospital), we used a unique patient identification number to allow tracking across databases and removed those that were captured in both databases for the same asthma event. As health care in Canada is available through a publicly funded system, the demographics of Windsor residents are assumed to be representative of patients receiving care in the Windsor medical facilities.

Health outcome variables. Asthma measures collected as part of the greater GeoDHOC study include prevalence rates and acute asthma events. Asthma prevalence, defined as the number of affected individuals normalized to the serviced population residing within each environmental assessment area, was determined using diagnostic coding from clinical encounters. Acute asthma events were assessed by enumerating both 
a

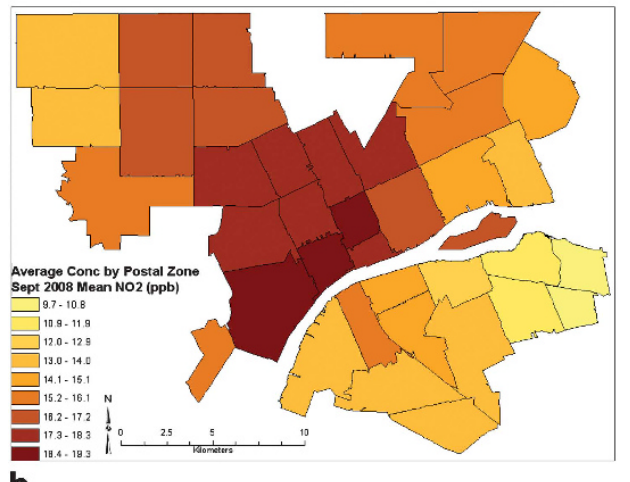

b

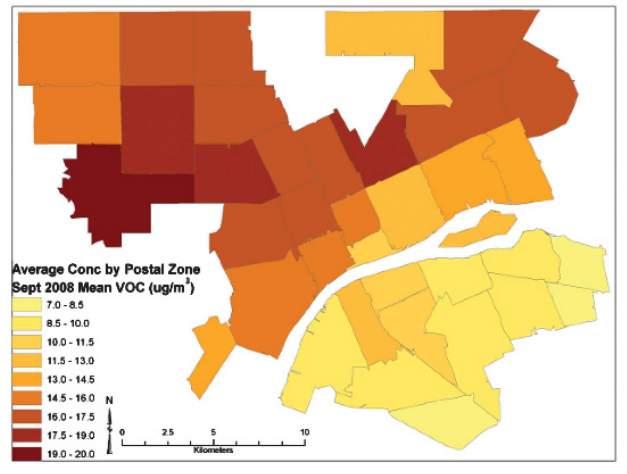

C

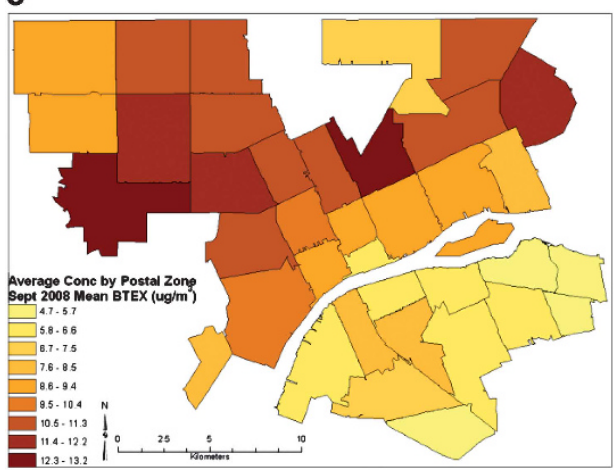

d

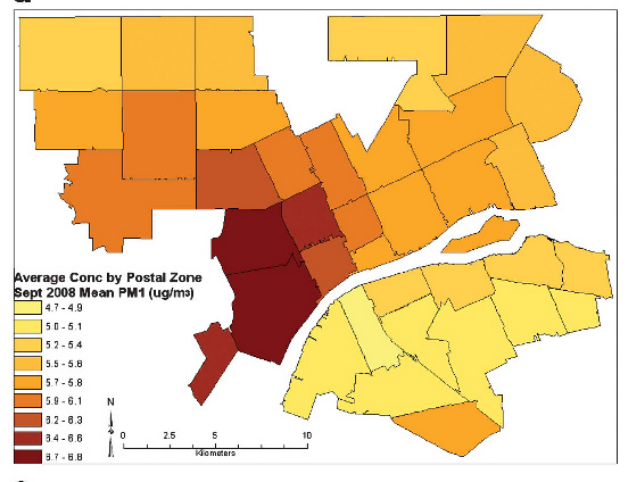

e

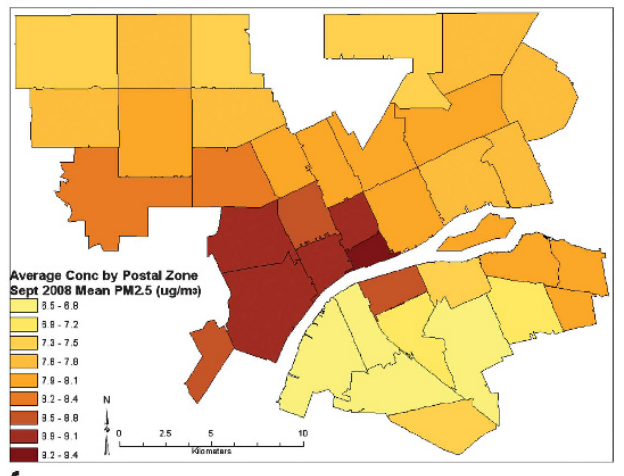

f

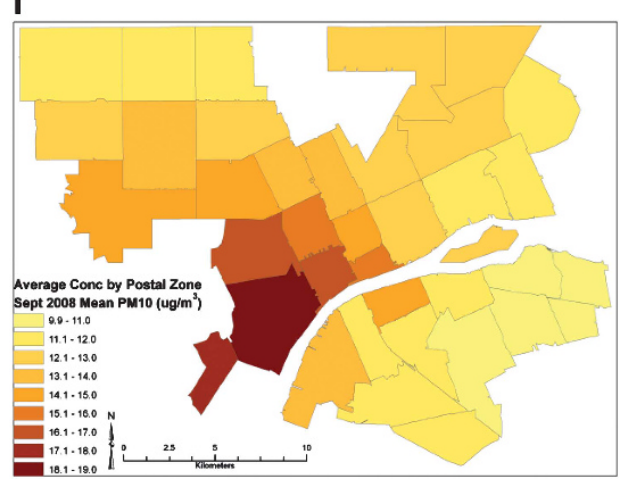

Figure 3. Average September 2008 concentration by postal zone for: (a) $\mathrm{NO}_{2}$ (p.p.b.); (b) $\mathrm{VOC}\left(\mu \mathrm{g} / \mathrm{m}^{3}\right) ;(\mathbf{c}) \mathrm{BTEX}\left(\mu \mathrm{g} / \mathrm{m}^{3}\right) ;(\mathbf{d}) \mathrm{PM},\left(\mu \mathrm{g} / \mathrm{m}^{3}\right)$; (e) $\mathrm{PM}_{2.5}\left(\mu \mathrm{g} / \mathrm{m}^{3}\right)$; and (f) $\mathrm{PM}_{10}\left(\mu \mathrm{g} / \mathrm{m}^{3}\right)$.

hospital admissions and emergency department visits with primary diagnoses of asthma. Service date and the appropriate ICD9-CM codes (493.xx) or ICD-10 code (J45) were used to identify health data for analysis. Descriptive analyses were used to characterize asthma morbidity in the population by age, gender, race, residence, and other sociodemographic variables. Geocoding by residential address was used to assign a spatial location to health outcome event records in Detroit, and Windsor records were assigned to the appropriate postal forward sortation area based on residential address. Acute asthma counts within each postal code area were stratified by age and gender to account for spatial differences in the underlying age-sex distribution of the study population. Institutional Review Board approval for the study was obtained from the participating institutions and all personal and health information was de-identified and coded to protect the identity of individuals.

\section{Spatial Correlation of Air Quality and Health Data}

Interpolated models of air pollutant concentrations across Detroit and Windsor were generated on a $300 \times 300 \mathrm{~m}$ grid using ordinary kriging with variogram parameters derived for the entire Detroit-Windsor study area. ${ }^{32}$ Contour maps were created from these grids to depict the spatial distribution of measured analytes, including $\mathrm{PM}_{2.5}$ and $\mathrm{PM}_{10}$, which were obtained by summing grids for the measured $\mathrm{PM}_{1}$ plus $\mathrm{PM}_{1-2.5}$, and $\mathrm{PM}_{2.5}$ plus $\mathrm{PM}_{2.5-10}$ components, respectively. Average concentration values for postal zones (5-digit zip code tabulation areas in Detroit and 3-digit forward sortation areas in Windsor) were calculated from the kriged models using spatial analyst tools in ArcGIS. The density of asthma occurrences, geocoded by patient residence address and normalized to patient population (i.e., persons with residential addresses in Detroit receiving health care from HFHS during 2008 and total population of Windsor in 2006), was determined for individual postal zones in Detroit and Windsor. Pearson correlation coefficients and regression coefficients were calculated to assess the strength of associations between rates of acute asthma events and corresponding average concentrations of measured pollutants in each postal zone. Zip codes 48203 (Highland Park) and 48212 (Hamtramck) were excluded in Detroit and forward sortation area N8N was excluded in Windsor because these postal zones include significant numbers of residents living outside the city boundaries. In addition, health information was not available for forward sortation area N8V.

\section{RESULTS}

Ambient Concentrations and Distributions

Aggregated data for selected 2008 and 2009 air pollutant concentrations across the two metropolitan regions are presented 


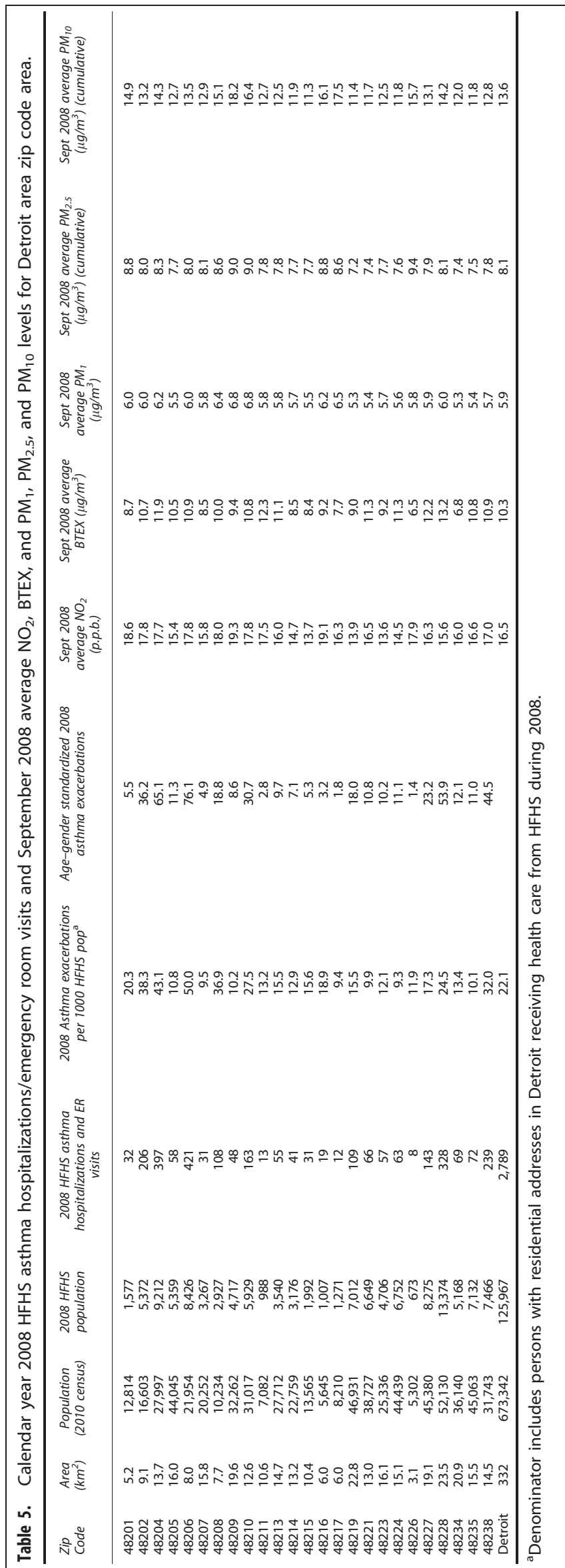

in Table 4. A more detailed description and analysis of the September 2008 measurements and spatial distributions of airborne contaminants was reported by Miller et al. ${ }^{32,42}$ Mapped distributions of September $2008 \mathrm{NO}_{2}$, total VOCs, total BTEX, PM, $\mathrm{PM}_{2.5}$, and $\mathrm{PM}_{10}$ concentrations are shown on Figure 2. Spatial variability is readily apparent between and within both cities. Concentrations of the September 2008 mapped pollutants averaged across each postal zone using ArcGIS are shown in Figure 3.

An independent sample $t$-test was used to evaluate the statistical significance of differences between mean concentrations measured in Detroit versus Windsor for each analyte. In 2008 the mean concentration of $\mathrm{NO}_{2}, \mathrm{BTEX}, \mathrm{VOCs}, \mathrm{PAHs}, \mathrm{PM}_{1}$, and $\mathrm{PM}_{10}$ were significantly higher $(P<0.05)$ in Detroit than Windsor. In 2009, mean concentrations of $\mathrm{NO}_{2}, \mathrm{BTEX}$, and VOCs were higher in Detroit and the mean concentration of $\mathrm{SO}_{2}$ was higher in Windsor (Table 4).

Comparisons of concentration variance suggest greater variability for some analytes within Windsor. The coefficients of variance $(\mathrm{CV})$, obtained by dividing the standard deviation by the mean (Table 4), were consistently greater in Windsor for $\mathrm{NO}_{2}$, $\mathrm{PAHs}, \mathrm{PM}_{1}, \mathrm{PM}_{2.5}$, and $\mathrm{PM}_{10}$ in 2008 and 2009, although CVs for VOCs were lower in Windsor.

Health Outcomes and Correlations with Ambient Concentrations In Detroit, HFHS asthma-related health-care visits were apportioned by zip code tabulation area corresponding to each patient's residential address (Table 5). Approximately 3000 hospitalizations and ER visits were recorded at HFHS facilities for primary diagnosis of asthma for patients residing in the study area during 2008. In Windsor, asthma-related health-care visits quantified using hospital discharges and emergency room visits were apportioned to Canadian forward sortation areas corresponding to the patients' residential address (Table 6). The density of asthma occurrences for individual postal zones in Detroit and Windsor is shown in Figure 4.

Visual comparison of Figure 4 with September 2008 air pollutant concentrations averaged by postal zone (Figure 3) suggests potential relationships between the standardized number of asthma events and concentrations of some pollutants in Detroit and Windsor. With the exception of $\mathrm{PM}_{2.5}$ and $\mathrm{PM}_{10}$ in Detroit and $\mathrm{PM}_{1}$ in Windsor, positive correlations are apparent in scatter plots of age-gender-standardized asthma events versus average pollutant concentrations by postal zone for Detroit (Figure 5) and Windsor (Figure 6). Although these plots display a fair degree of scatter, correlation and regression slope coefficients (Table 7) demonstrate moderate to strong postal code scale associations between standardized asthma events and $\mathrm{NO}_{2}$, VOCs and $\mathrm{PM}_{10}$ in Windsor, as well as BTEX and VOCs in Detroit.

\section{DISCUSSION}

The observed association between $\mathrm{NO}_{2}$ and acute asthma events in Windsor adds to a growing number of studies linking asthma morbidity to higher levels of $\mathrm{NO}_{2}$ in other cities. Using coarse measures of $\mathrm{NO}_{2}$ to estimate exposure, Hajat et al. ${ }^{43}$ found an association between $\mathrm{NO}_{2}$ and general practitioner consultations for asthma in London, England. More recently, Ko et al. ${ }^{17}$ reported a significant association between asthma hospitalization rates and $\mathrm{NO}_{2}$ in Hong Kong while Ho et al. ${ }^{44}$ found a significant relationship between adolescents' asthma attack rates and $\mathrm{NO}_{2}$ in Hong Kong. A number of studies citing the production of $\mathrm{NO}_{2}$ as a byproduct of roadway traffic also support an association between roadway and other point/non-point source proximity and asthma outcomes. For example, Oyana et al. ${ }^{45}$ documented the clustering of adult asthma outpatient visits and hospitalizations near roadways and a significant bridge complex in Buffalo, New York. Similarly, Newcomb and $\mathrm{Li}^{46}$ concluded that 


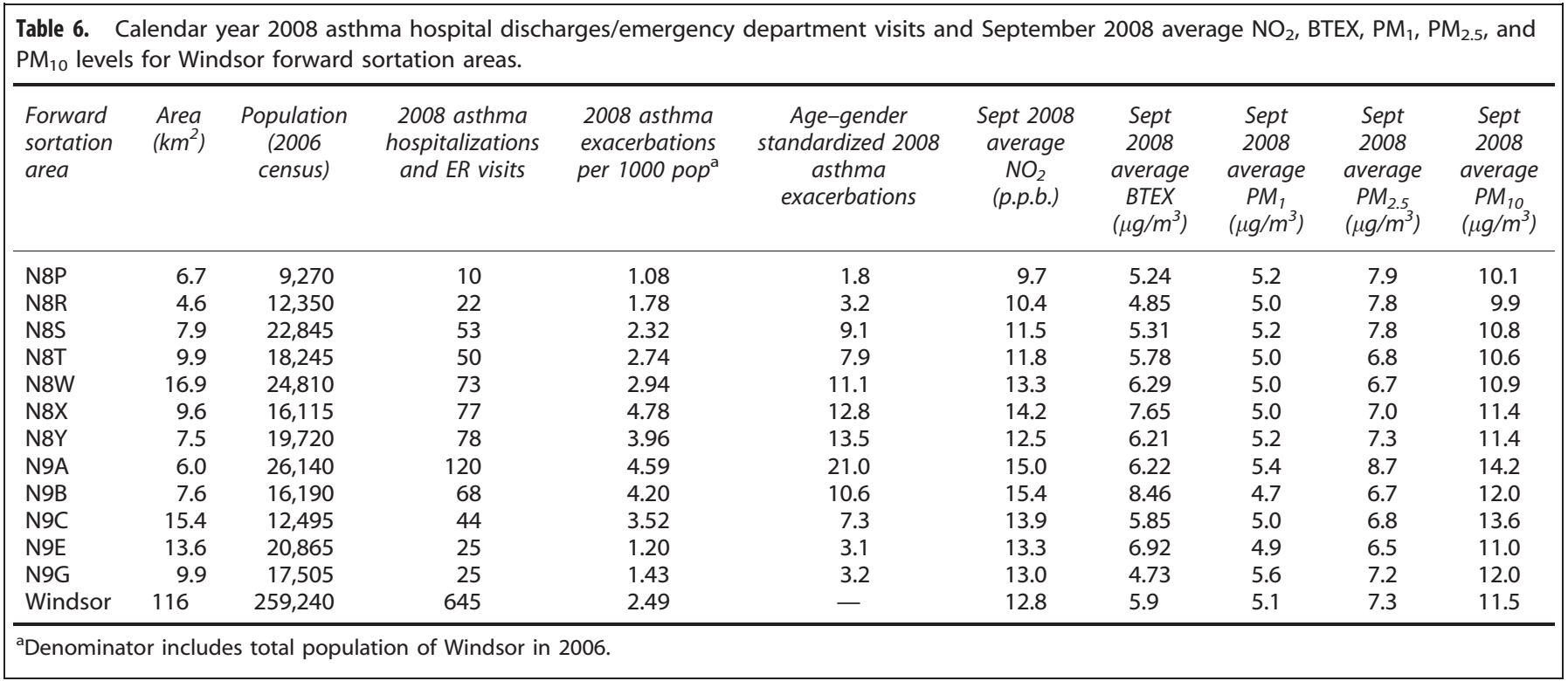

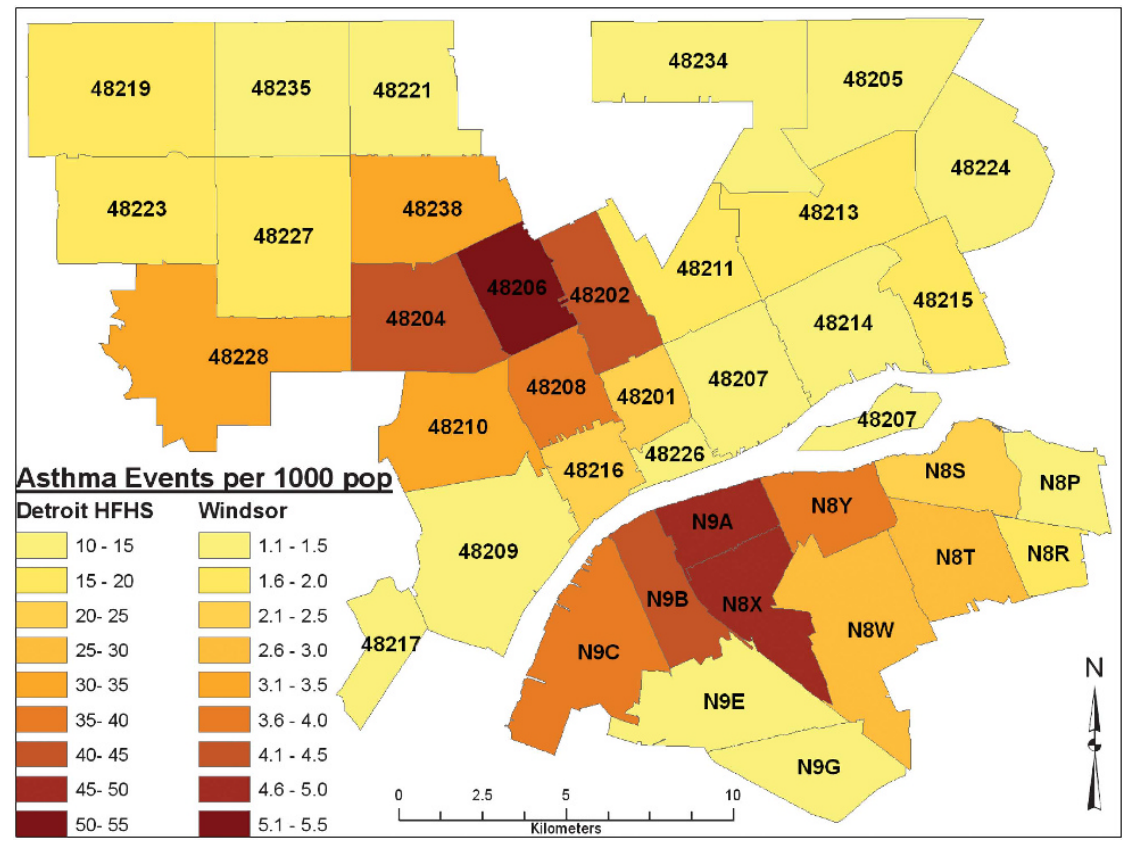

Figure 4. Year 2008 asthma events per 1000 population by postal code area. Note different scales for Detroit and Windsor.

proximity to major roadways is a strong predictor of emergency department admission or hospitalization among children in Terrant County, Texas. In contrast, Lewis et al. ${ }^{47}$ did not find an association between roadway proximity and physician-diagnosed asthma or asthma medication in east England, and Meng et al. ${ }^{48}$ reported the lack of a significant relationship between poorly controlled asthma in adults and $\mathrm{NO}_{2}$ measurements from government air monitoring stations in Los Angeles and San Diego, California, USA.

The observed associations between asthma and VOCs in Detroit and Windsor contribute to a small number of studies examining relationships between asthma and VOC concentrations, although comparisons to published studies are complicated by differences in how VOC data are reported. Weichenthal et al. ${ }^{49}$ reviewed six studies investigating indoor VOC exposure and childhood asthma. Three of those studies included only formaldehyde, which was not included in our analysis. The results for the other three studies were mixed with two reporting significant asthma risk associated with VOCs and one finding no increase in asthma risk or morbidity linked to total VOCs. Arif and Shah ${ }^{50}$ found that physiciandiagnosed asthma and the presence of wheezing in US adults was significantly related to increased exposure to separate groupings of four aromatic compounds (BTEX) and two chlorinated hydrocarbons (tetrachloroethene and trichloroethene) measured with passive personal exposure monitors. Kim et al. ${ }^{51}$ studied biomarkers of VOC exposure (i.e., hippuric and muconic acid), and their relation to childhood asthma. They reported a significant increase of muconic acid in subjects with asthma.

With respect to particulate matter and acute asthma events, our results are mixed. We found a significant association between asthma and $\mathrm{PM}_{10}$ in Windsor, but correlations for other size fractions were not significant in either city. Although comparison 

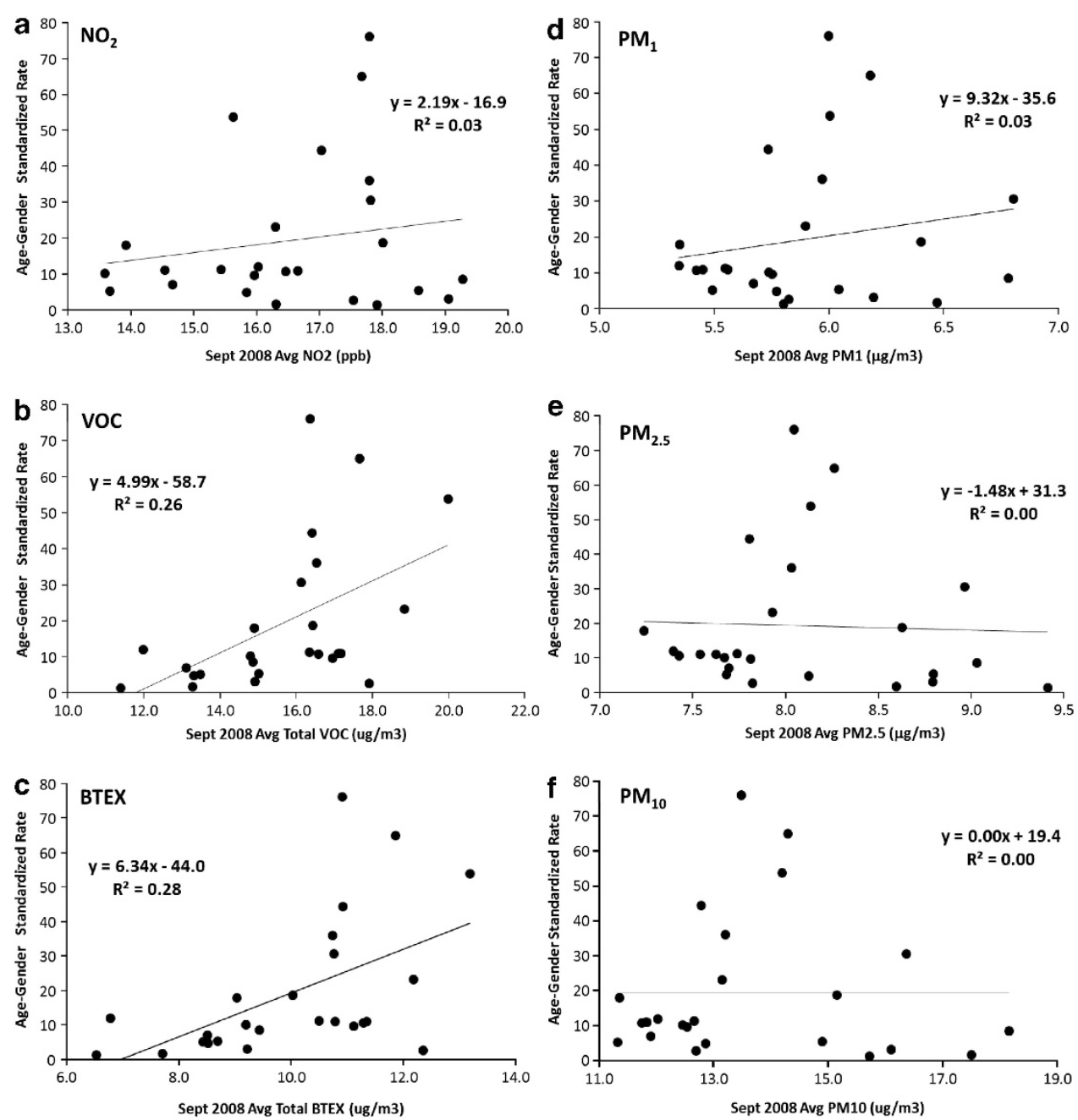

Figure 5. Detroit 2008 calendar year age-gender standardized HFHS asthma rate versus average September 2008 concentration by zip code for: (a) $\mathrm{NO}_{2}$; (b) VOC; (c) BTEX; (d) $\mathrm{PM}_{1} ;$ (e) $\mathrm{PM}_{2.5}$; and (f) $\mathrm{PM}_{10}$. Lines show best fit linear regression.

is sometimes confounded by inconsistent reporting of PM size fractions in the literature, results of other studies are also mixed. Meng et al. ${ }^{48}$ demonstrated a relationship between poorly controlled asthma and $\mathrm{PM}_{10}$ measured at government air monitoring stations in Los Angeles and San Diego, California, primarily in women; however, significant associations with $\mathrm{PM}_{2.5}$ were not observed. Hajat et al. ${ }^{43}$ found that $\mathrm{PM}_{10}$ concentrations measured at a central monitoring site were positively related to asthma treatments by general practitioners in London. Ko et al. ${ }^{17}$ also reported that $\mathrm{PM}_{2.5}$ and $\mathrm{PM}_{10}$ were both significantly associated with asthma hospitalization rates in Hong Kong. Conversely, although trends in their data suggested a relationship with lung function, Tang et al. ${ }^{52}$ reported no statistically significant results linking $\mathrm{PM}_{1}, \mathrm{PM}_{2.5}$, or $\mathrm{PM}_{10}$ (assessed with personal monitors) to peak expiratory flow rate for asthmatic children in Sin-Chung City, Taiwan. Slaughter et al. ${ }^{53}$ also reported a lack of statistically significant associations among four PM size fractions and hospitalizations or ER visits for asthma in Spokane, Washington.

The GeoDHOC study has several important limitations. First, it relies upon ambient air pollutant concentrations for exposure estimates and does not address personal exposures of the study population within individual residences or places of occupation. Second, the collection of integrated air pollutant measurements over 2-week sampling periods misses daily or diurnal fluctuations in air pollutants such as traffic-derived $\mathrm{NO}_{2}$. This coarse temporal resolution was a necessary tradeoff of the study design incorporating a large number of samplers to increase spatial resolution. Third, the results reported here compare pollution measurements in September to asthma events recorded throughout a calendar year without accounting for seasonal variation. Prior studies in Windsor examining air pollutant variability across four seasons (summer, winter, spring, and fall) in 2004-06 found significant correlations among all seasons for $\mathrm{NO}_{2}, \mathrm{SO}_{2}$, and BTEX, suggesting a reasonable degree of consistency in source distributions for $\mathrm{NO}_{2}$ and VOCs throughout the year. ${ }^{21,54}$ Fourth, we drew acute asthma events from two different health databases representing populations from different countries and health-care delivery systems. The results reported here do not explicitly account for sociodemographic differences between Detroit and Windsor, nor do they account for potential differences in diagnoses and coded services between the populations. Moreover, by relying on hospital visit administrative data only, the study does not take into account the role that management of disease may have in exacerbation. Significant differences in any or all of these factors potentially could engender ecological fallacies arising from individual-level conclusions drawn from aggregate health effect estimates. ${ }^{55}$

One noteworthy difference between Detroit and Windsor is the number of acute asthma events observed per 1000 population. 

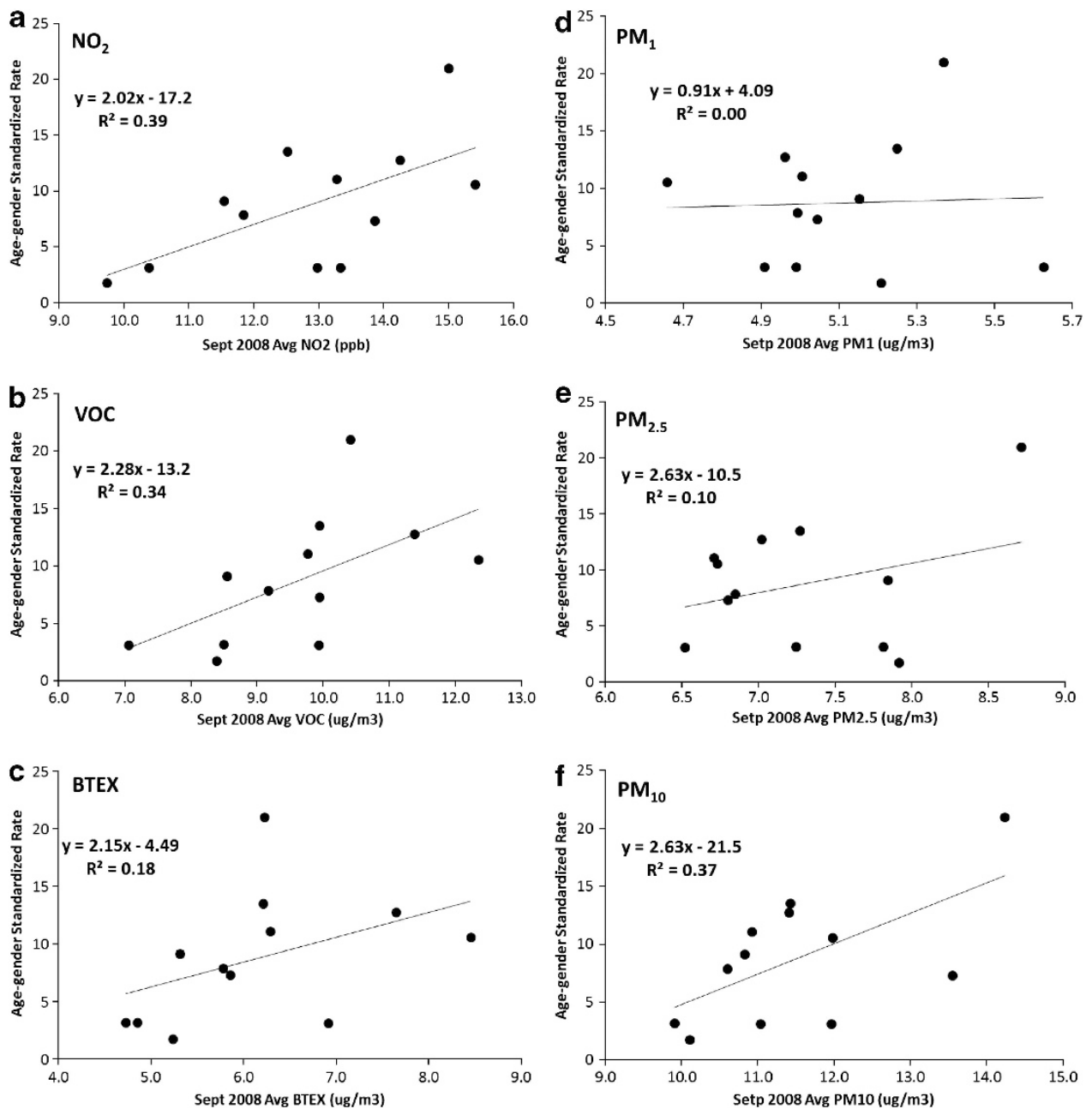

Figure 6. Windsor 2008 calendar year age-gender standardized asthma rate versus average September 2008 concentration by forward sortation area for: (a) $\mathrm{NO}_{2}$; (b) VOC; (c) BTEX; (d) $\mathrm{PM}_{1} ;$ (e) $\mathrm{PM}_{2.5}$; and (f) $\mathrm{PM}_{10}$. Lines show best fit linear regression.

Table 7. Linear regression slope ( $\beta 1$ values) and Pearson correlation coefficients $(r)$ for air pollutant concentrations and asthma events by postal zone in 2008 (data in Tables 5 and 6).

\begin{tabular}{|c|c|c|c|c|c|c|c|c|c|c|}
\hline & \multicolumn{5}{|c|}{ Detroit } & \multicolumn{5}{|c|}{ Windsor } \\
\hline & $\beta 1$ & $95 \% \mathrm{Cl}$ & $r$ & $95 \% \mathrm{Cl}$ & P & $\beta 1$ & $95 \% \mathrm{Cl}$ & $r$ & $95 \% \mathrm{Cl}$ & $\mathrm{P}$ \\
\hline $\mathrm{NO}_{2}$ & 2.19 & - & 0.17 & - & 0.40 & 2.02 & $1.23-2.81$ & 0.63 & $0.08-0.88$ & 0.03 \\
\hline BTEX & 6.34 & $4.23-8.45$ & 0.53 & $0.17-0.77$ & 0.01 & 2.15 & - & 0.43 & - & 0.16 \\
\hline VOC & 4.99 & $3.23-6.75$ & 0.51 & $0.14-0.75$ & 0.01 & 2.28 & $1.27-3.29$ & 0.58 & $0.01-0.87$ & 0.05 \\
\hline $\mathrm{PAH}$ & 0.42 & - & 0.09 & - & 0.68 & 0.34 & - & 0.38 & - & 0.23 \\
\hline $\mathrm{PM}_{1}$ & 9.32 & - & 0.19 & - & 0.38 & 0.91 & - & 0.04 & - & 0.90 \\
\hline $\mathrm{PM}_{2.5}$ & -1.48 & - & -0.04 & - & 0.84 & 2.63 & - & 0.31 & - & 0.33 \\
\hline $\mathrm{PM}_{10}$ & 0.00 & - & 0.00 & - & 1.00 & 2.63 & $1.55-3.71$ & 0.61 & $0.06-0.88$ & 0.04 \\
\hline
\end{tabular}

95\% confidence intervals given for significant values $(P<0.05)$ shown in bold.

The average population-normalized asthma events for HFHS patients in Detroit zip codes (Table 5 , column 6 ) is $\sim 10$ times greater than the average number of asthma events in Windsor forward sortation areas (Table 6, column 5). Part of this discrepancy is attributable to the difference in denominator specification between the two cities (i.e., HFHS patients receiving health care in Detroit versus total population of Windsor). However, rates for Detroit are consistent with recent reports of 5.1 asthma hospitalizations per 1000 Detroit residents, and 33.6 asthma emergency department visits per 1000 Detroit children ( $\leq 18$ years) in $2004-2006 .{ }^{56}$ Moreover, HFHS utilization rates for Detroit residents in 2008 are also consistent with rates for 2007 and 2009, indicating that 2008 is not anomalous. Therefore, other factors inherent to the complexity of comparing health outcomes between cities in different countries are also likely to contribute to this disparity. For instance, differences in demographics including contrasts in income and ethnic and racial composition are readily apparent between Detroit and Windsor. In addition, Canada uses a 
universal health-care model while the USA has a multiplicity of payer methods and a significant proportion of uninsured residents. HFHS is a private, nonprofit organization serving both commercially insured persons (largely employer-paid plans), government-financed insured persons (Medicare for the elderly and Medicaid for the indigent), as well as a significant portion of uninsured persons. Records indicate 19\% of the HFHS asthma patients in this study received uncompensated care, and an additional $30 \%$ relied upon non-commercial insurance with variable benefits (e.g., uncovered ambulatory care), potentially elevating emergency care utilization rates in Detroit.

Beta values for BTEX and VOCs in Detroit exceed those for NO2, VOC, and PM10 in Windsor (Table 7), indicating a potentially greater increment of standardized acute asthma events per unit increase in ambient concentrations in Detroit. Conversely, higher correlation coefficients between standardized asthma events and pollutant concentrations were observed in Windsor. Nevertheless, the $95 \%$ confidence range of $r$ values overlaps for all significant associations (Table 7), indicating $r$ values are not distinguishable from each other or between the two cities. Hence, although average concentrations of air pollutants found in Detroit were generally higher than those found in Windsor (Table 4), the larger slope factors for BTEX and total VOCs observed in Detroit (Table 7) do not necessarily indicate stronger associations with asthma exacerbations in Detroit compared with Windsor. Rather, these initial results underscore the need for more rigorous investigation of how differences in population demographics, access to health care, and asthma management practices help to explain the observed differences in air pollution-health associations between the two cities.

Despite this study's limitations, the potential to use spatial models of airborne pollutant concentrations to estimate exposure associated with asthma morbidity in Detroit and Windsor is encouraging. As new quantitative methods are developed to aggregate and incorporate health and environmental information collected at different geospatial scales, ${ }^{57,58}$ they will have an increasingly important role in modeling, exposure estimation, and hypothesis testing in epidemiological studies. ${ }^{59}$ Indeed, recent investigations highlight the importance of geographic scale in detecting racial disparities in health outcomes. ${ }^{60,61}$ For most of the analytes included in this study, observed concentration gradients change across distances smaller than the dimensions of the zip code regions or postal sortation areas used to aggregate asthma events and pollution concentrations. We postulate therefore that analysis at a finer spatial resolution (i.e. census tract or block scale) can improve correlations between ambient air quality measurements and asthma health outcome variables, provided that a sufficient population resides within each geographic subdivision to maintain statistical power.

In summary, concentration maps for the suite of measured contaminants demonstrate neighborhood scale spatial variability of air toxics distributions in Detroit and Windsor. Statistically significant positive associations between acute asthma events and $\mathrm{NO}_{2}$, VOCs, BTEX, and $\mathrm{PM}_{10}$ concentrations were found at postal code scale resolution in one or both cities. Further study is needed to examine whether the air-health effects observed in 2008 remain consistent in 2009 or whether the average value of the two sampling campaigns is a better proxy of exposure. Additional study is also required to investigate the degree to which the observed correlations were affected by the chosen level of spatial resolution, individual measurement points, synergistic effects of exposure to multiple air pollutants, community-level characteristics that can modify associations between air pollution and some health outcomes, or by other as yet unrecognized factors.

\section{CONFLICT OF INTEREST}

The authors declare no conflict of interest.

\section{ACKNOWLEDGEMENTS}

This study was supported by the Wayne State University Research Enhancement Program for Clinical Translational Science in Urban Health, the University of Windsor Office of the Vice President for Research, Henry Ford Health System, and Health Canada. We gratefully acknowledge technical and logistical support from David Lowrie and Gianluca Sperone, and scientific contributions from members of the GeoDHOC team including Linda Weglicki, Alice Grgicak-Mannion, Richard Krajenta, Amanda Wheeler, Hongyu You, Lindsay Miller, Shannon Bobryk, Christina Baker Hongcheng Zeng, and Phil Graniero. We would also like to thank the Detroit Fire Department, Detroit Public Lighting, the Detroit Department of Environmental Affairs, Enwin Utilities, and many other organizations in Windsor for their cooperation.

\section{REFERENCES}

1 Bhatnagar A. Environmental cardiology: studying mechanistic links between pollution and heart disease. Circ Res 2006; 99: 692-705.

2 Kaufman JD. Air pollution and mortality: are we closer to understanding the how? Am J Respir Crit Care Med 2007; 176: 325-326.

3 Jerrett M, Shankardass K, Berhane K, Gauderman WJ, Kunzli N, Avol E et al. Traffic-related air pollution and asthma onset in children: a prospective cohort study with individual exposure measurement. Environ Health Perspect 2008; 116 1433-1438

4 Morgenstern V, Zutavern A, Cyrys J, Brockow I, Gehring U, Koletzko S et al. Respiratory health and individual estimated exposure to traffic-related air pollutants in a cohort of young children. Occup Environ Med 2007; 64: 8-16.

5 Villeneuve PJ, Chen L, Rowe BH, Coates F. Outdoor air pollution and emergency department visits for asthma among children and adults: a case-crossover study in northern Alberta, Canada. Environ Health 2007; 6: 40.

6 Chen $\mathrm{H}$, Goldberg MS, Villeneuve PJ. A systematic review of the relation between long-term exposure to ambient air pollution and chronic diseases. Rev Environ Health 2008; 23: 243-297.

7 Stroh E, Rittner R, Oudin A, Ardo J, Jakobsson K, Bjork J et al. Measured and modeled personal and environmental NO2 exposure. Popul Health Metr 2012; 10: 10.

8 World Health Organization. Air quality and health; Fact Sheet N313 2011, (updated September 2011). Available from http://www.who.int/mediacentre/ factsheets/fs313/en/index.html.

9 McConnell R, Berhane K, Gilliland F, London SJ, Islam T, Gauderman WJ et al. Asthma in exercising children exposed to ozone: a cohort study. Lancet 2002; 359 386-391.

10 Rios JL, Boechat JL, Sant'Anna CC, Franca AT. Atmospheric pollution and the prevalence of asthma: study among schoolchildren of 2 areas in Rio de Janeiro, Brazil. Ann Allergy Asthma Immunol 2004; 92: 629-634.

11 Hewitt CN. Spatial variations in nitrogen-dioxide concentrations in an urban area. Atmos Environ B-Urb 1991; 25: 429-434.

12 Zhu YF, Hinds WC, Kim S, Shen S, Sioutas C. Study of ultrafine particles near a major highway with heavy-duty diesel traffic. Atmos Environ 2002; 36: 4323-4335

13 Zhu YF, Hinds WC, Kim S, Sioutas C. Concentration and size distribution of ultrafine particles near a major highway. J Air Waste Manage 2002; 52: 1032-1042.

14 Jerrett M, Burnett RT, Ma RJ, Pope CA, Krewski D, Newbold KB et al. Spatial analysis of air pollution and mortality in Los Angeles. Epidemiology 2005; 16: 727-736.

15 Miller KA, Siscovick DS, Sheppard L, Shepherd K, Sullivan JH, Anderson GL et al. Long-term exposure to air pollution and incidence of cardiovascular events in women. N Engl J Med 2007; 356: 447-458.

16 Molitor J, Jerrett M, Chang CC, Molitor NT, Gauderman J, Berhane K et al. Assessing uncertainty in spatial exposure models for air pollution health effects assessment. Environ Health Perspect 2007; 115: 1147-1153.

17 Ko FW, Tam W, Wong TW, Lai CK, Wong GW, Leung TF et al. Effects of air pollution on asthma hospitalization rates in different age groups in Hong Kong. Clin Exp Allergy 2007; 37: 1312-1319.

18 Rodriguez C, Tonkin R, Heyworth J, Kusel M, De Klerk N, Sly PD et al. The relationship between outdoor air quality and respiratory symptoms in young children. Int J Environ Heal R 2007; 17: 351-360.

19 Spicer CW, Buxton BE, Holdren MW, Smith DL, Kelly TJ, Rust SW et al. Variability of hazardous air pollutants in an urban area. Atmos Environ 1996; 30 $3443-3456$

20 Luginaah I, Xu X, Fung KY, Grgicak-Mannion A, Wintermute J, Wheeler A et al. Establishing the spatial variability of ambient nitrogen dioxide in Windsor, Ontario. Int J Environ Stud 2006; 63: 487-500.

21 Wheeler AJ, Smith-Doiron M, Xu X, Gilbert NL, Brook JR. Intra-urban variability of air pollution in Windsor, Ontario-Measurement and modeling for human exposure assessment. Environ Res 2008; 106: 7-16. 
22 Wheeler AJ, Xu X, Kulka R, You H, Wallace L, Mallach G et al. Windsor, Ontario exposure assessment study: design and methods validation of personal, indoor, and outdoor air pollution monitoring. J Air Waste Manag Assoc 2011; 61: 324-338.

23 Lavigne E, Villeneuve PJ, Cakmak S. Air pollution and emergency department visits for asthma in Windsor, Canada. Can J Public Health 2012; 103: 4-8.

24 DATPS. Data analyses for Detroit, Michigan, Air Toxics Data Collections in 2001 2004, Sonoma Technology final report STI-903553-2557-FR.

25 Williams R, Rea A, Vette A, Croghan C, Whitaker D, Stevens C et al. The design and field implementation of the Detroit Exposure and Aerosol Research Study. J Expo Sci Env Epid 2009; 19: 643-659.

26 Rodes CE, Lawless PA, Thornburg JW, Williams RW, Croghan CW. DEARS particulate matter relationships for personal, indoor, outdoor, and central site settings for a general population. Atmos Environ 2010; 44: 1386-1399.

27 Thornburg J, Rodes CE, Lawless PA, Williams R. Spatial and temporal variability of outdoor coarse particulate matter mass concentrations measured with a new coarse particle sampler during the Detroit Exposure and Aerosol Research Study. Atmos Environ 2009; 43: 4251-4258.

28 Barzyk TM, George BJ, Vette AF, Williams RW, Croghan CW, Stevens CD. Development of a distance-to-roadway proximity metric to compare near-road pollutant levels to a central site monitor. Atmos Environ 2009; 43: 787-797.

29 Williams R, Jones P, Croghan C, Thornburg J, Rodes C. The influence of human and environmental exposure factors on personal NO2 exposures. J Expo Sci Env Epid 2012; 22: 109-115.

30 USEPA. United States Environmental Protection Agency, Toxics Release Inventory (TRI) Program 2013, Available from http://www.epa.gov/tri/.

31 Environment Canada. Canadian National Pollutant Release Inventory 2013, Available from http://www.ec.gc.ca/inrp-npri/.

32 Miller L, Lemke LD, Xu XH, Molaroni SM, You HY, Wheeler AJ et al. Intra-urban correlation and spatial variability of air toxics across an international airshed in Detroit, Michigan (USA) and Windsor, Ontario (Canada). Atmos Environ 2010; 44: 1162-1174.

33 Kanaroglou PS, Jerrett M, Morrison J, Beckerman B, Arain MA, Gilbert NL et al. Establishing an air pollution monitoring network for intra-urban population exposure assessment: A location-allocation approach. Atmos Environ 2005; 39: 2399-2409.

34 Smith L, Mukerjee S, Gonzales M, Stallings C, Neas L, Norris G et al. Use of GIS and ancillary variables compound and nitrogen dioxide to predict volatile organic levels at unmonitored locations. Atmos Environ 2006; 40: 3773-3787.

35 Mukerjee S, Oliver KD, Seila RL, Jacumin HH, Croghan C, Daughtrey EH et al. Field comparison of passive air samplers with reference monitors for ambient volatile organic compounds and nitrogen dioxide under week-long integrals. J Environ Monitor 2009; 11: 220-227.

36 National Heart Lung and Blood Institute. How is Asthma Diagnosed? 2012, [updated June 15, 2012]Available from http://www.nhlbi.nih.gov/health/healthtopics/topics/asthma/diagnosis.html.

37 U.S. Census. United States Census 2010 2010, Available from http://www.census. gov/2010census/.

38 Statistics Canada 2006, Community Profiles 2006. Available from http:// www12.statcan.ca/census-recensement/2006/dp-pd/prof/92-591/index.cfm.

39 Erie St. Clair Local Health Integration Network. StrategiCare '08: Phase 1 Final Report 2008, Available from http://www.eriestclairlhinnews.on.ca/blog-strategicare/gallery/1/ StrategiCare\%2008\%20Phase\%201\%20Final\%20Report\%20September\%202008.pdf.

40 Canadian Institute for Health Information. Discharge Abstract Database (DAD) Metadata 2013, Available from http://www.cihi.ca/ClHI-ext-portal/internet/en/ document/types + of + care/hospital + care/acute + care/dad_metadata.

41 Canadian Institute for Health Information. National Ambulatory Care Reporting System (NACRS) 2013, Available from http://www.cihi.ca/ClHI-ext-portal/internet/en/ document/types + of + care/hospital + care/emergency + care/NACRS METADATA.

42 Miller L, Lemke LD, Xu XH, Molaroni SM, You HY, Wheeler AJ et al. Corigendum to 'Intra-urban correlation and spatial variability of air toxics across an international airshed in Detroit, Michigan (USA) and Windsor, Ontario (Canada)'. Atmos Environ 2012; 46: 683-686.
43 Hajat S, Haines A, Goubet SA, Atkinson RW, Anderson HR. Association of air pollution with daily GP consultations for asthma and other lower respiratory conditions in London. Thorax 1999; 54: 597-605.

44 Ho WC, Hartley WR, Myers L, Lin MH, Lin YS, Lien CH et al. Air pollution, weather, and associated risk factors related to asthma prevalence and attack rate. Environ Res 2007; 104: 402-409.

45 Oyana TJ, Rogerson P, Lwebuga-Mukasa JS. Geographic clustering of adult asthma hospitalization and residential exposure to pollution at a United StatesCanada border crossing. Am J Public Health 2004; 94: 1250-1257.

46 Newcomb P, Li J. Predicting admissions for childhood asthma based on proximity to major roadways. J Nurs Scholarsh 2008; 40: 319-325.

47 Lewis SA, Antoniak M, Venn AJ, Davies L, Goodwin A, Salfield N et al. Secondhand smoke, dietary fruit intake, road traffic exposures, and the prevalence of asthma: a cross-sectional study in young children. Am J Epidemiol 2005; 161: 406-411.

48 Meng YY, Wilhelm M, Rull RP, English P, Ritz B. Traffic and outdoor air pollution levels near residences and poorly controlled asthma in adults. Ann Allergy Asthma Immunol 2007; 98: 455-463.

49 Weichenthal S, Dufresne A, Infante-Rivard C. Indoor nitrogen dioxide and VOC exposures: Summary of evidence for an association with childhood asthma and a case for the inclusion of indoor ultrafine particle measures in future studies. Indoor Built Environ 2007; 16: 387-399.

50 Arif AA, Shah SM. Association between personal exposure to volatile organic compounds and asthma among US adult population. Int Arch Occup Environ Health 2007; 80: 711-719.

$51 \mathrm{Kim} \mathrm{JH}$, Kim JK, Son BK, Oh JE, Lim DH, Lee KH et al. Effects of air pollutants on childhood asthma. Yonsei Med J 2005; 46: 239-244.

52 Tang CS, Chang LT, Lee HC, Chan CC. Effects of personal particulate matter on peak expiratory flow rate of asthmatic children. Sci Total Environ 2007; 382: 43-51.

53 Slaughter JC, Kim E, Sheppard L, Sullivan JH, Larson TV, Claiborn C. Association between particulate matter and emergency room visits, hospital admissions and mortality in Spokane, Washington. J Expo Anal Environ Epidemiol 2005; 15: 153-159.

54 Miller L, Xu XH, Grgicak-Mannion A, Brook J, Wheeler A. Multi-season, multi-year concentrations and correlations amongst the BTEX group of VOCs in an urbanized industrial city. Atmos Environ 2012; 61: 305-315.

55 Greenland S. Ecologic versus individual-level sources of bias in ecologic estimates of contextual health effects. Int J Epidemiol 2001; 30: 1343-1350.

56 Wasilevich E, Lyon-Callo S, Rafferty A, Dombkowski K. Chapter 12: Detroit-The Epicenter of Asthma Burden 2009, In: Epidemiology of Asthma in Michigan [Internet]. Bureau of Epidemiology, Michigan Department of Community Health. Available from http://www.michigan.gov/documents/mdch/epi-mich-asthmaDetroit_Epicenter_of_Asthma_401493_7.pdf.

57 Goovaerts P. Combining Areal and Point Data in Geostatistical Interpolation: Applications to Soil Science and Medical Geography. Math Geosci 2010; 42: 535-554.

58 Goovaerts P. Geostatistical analysis of health data with different levels of spatial aggregation. Spat Spatiotemporal Epidemiol 2012; 3: 83-92.

59 Jacquez GM, Goovaerts $P$. The emerging role and benefits of boundary analysis in spatio-temporal epidemiology and public health. Spat Spatiotemporal Epidemiol 2010; 1: 197-200.

60 Goovaerts P, Meliker JR, Jacquez GM. A comparative analysis of aspatial statistics for detecting racial disparities in cancer mortality rates. Int J Health Geogr 2007; 6: 32

61 Tian N, Goovaerts P, Zhan FB, Wilson JG. Identification of racial disparities in breast cancer mortality: does scale matter? Int J Health Geogr 2010; 9: 35.

(c) (9) This work is licensed under a Creative Commons AttributionBY NG SA NonCommercial-ShareAlike 3.0 Unported License. To view a copy of this license, visit http://creativecommons.org/licenses/by-nc-sa/3.0/ 